\title{
Determination of the Incidence of Medicolegal Death in a Tertiary Health Institution in Abakaliki, Ebonyi State, South-East, Nigeria
}

\author{
Felix O. Edegbe ${ }^{1}$, Chukwuma J. Uzoigwe ${ }^{1}$, Kenneth C. Ekwedigwe ${ }^{3}$, Chukwudi O. Okani ${ }^{2}$, Uzoma M. Agwu ${ }^{2}$, \\ Johnbosco Nwafor ${ }^{3} \&$ Paul I. Ekwedigwe ${ }^{3}$ \\ ${ }^{1}$ Department of Morbid Anatomy, Alex-Ekwueme Federal University Teaching Hospital, Abakaliki, Nigeria \\ ${ }^{2}$ Department of Histopathology, Chukwuemeka Odumegwu Ojukwu University, Awka Campus, Nigeria \\ ${ }^{3}$ Department of Obstetrics and Gynaecology, Alex-Ekwueme Federal University Teaching Hospital, Abakaliki, \\ Nigeria \\ Correspondence: Dr Kenneth Chinedu Ekwedigwe, Department of Obstetrics and Gynaecology, Alex-Ekwueme \\ Federal University Teaching Hospital, Abakaliki, Ebonyi Stat, Nigeria. E-mail: ekwedigwe@yahoo.com
}

Received: November 20, 2019 Accepted: January 25, 2020 Online Published: June 8, 2020

doi:10.5539/gjhs.v12n8p58

URL: https://doi.org/10.5539/gjhs.v12n8p58

\begin{abstract}
Background: Death is an inevitable end that comes when not expected. However, when death occurs as a result of violence or unclear and suspicious manner, a coroner inquest is instituted to determine the cause, manner and the mechanism of death.
\end{abstract}

Aim: To determine the incidence and causes of medicolegal death in Ebonyi State.

Materials and Method: This is a 5-year retrospective study of medicolegal autopsies reports of subjects whose cause of death were subject of litigation. The study analysed data between January 1, 2013, and December 31, 2017, at Alex Ekwueme Federal University Teaching Hospital, Ebonyi, Southeast, Nigeria. Data analysis was with the SPSS version 20.

Results: During the study period. A total number of 202 autopsies were performed. The age range of the deceased was from 2 years to 90 years, with a mean age of $35.2 \pm 16.1$. The predominant age group was $30-39$ years $(30.2 \%)$ while the least $(0.5 \%)$ were between the age of 90 and 99 years. Males accounted for $158(78.2 \%)$, and females were $44(21.8 \%)$. Farmers $(31.2 \%)$ and students $(15.3 \%)$ were mostly affected by unnatural death in this study. Accidental deaths constituted $54.5 \%$ of cases, followed by homicidal death (36.6\%). Impalement by sharp objects $(41.9 \%)$ was a significant cause of death due to homicide in this study. In contrast, accidental deaths were mainly as a result of a road traffic accident $(95.5 \%)$. The majority (60.4\%) of those who died as a result of an accident sustained an injury at multiple body sites.

Conclusion: Road traffic accident and homicide were responsible for the majority of cause of death found in medicolegal autopsies in Ebonyi State. Proper road maintenance, safe driving culture, and making people adhere strictly to the rule of law are necessary to reduce the incidence of avoidable deaths in our environment.

Keywords: Incidence, medicolegal death, Ebonyi State, Nigeria

\section{Introduction}

An autopsy is a clinicopathological investigation on a deceased body to unravel the cause of death (Akhiwu, Nwosu, \& Aligbe, 2000). Autopsies are grouped into medicolegal, clinical, anatomical and virtual autopsies (Duduyemi \& Ojo, 2013). Medicolegal autopsies are postmortem examination performed on a deceased body at the instruction of the law to determine the cause of death and circumstance surrounding the death (Akhiwu, Nwosu, \& Aligbe, 2000; Duduyemi \& Ojo, 2013). Medicolegal deaths are classified based on the manner of death as natural, accidental, suicidal, homicidal and undetermined (Offia \& Obiorah, 2014; Obiorah \& Amakiri, 2014; Amakiri et al., 1997).

Medicolegal autopsies are conducted through the issuance of coroner forms by a coroner or any other authority as stipulated by the constitution of the country of practice (Duduyemi \& Ojo, 2013). Different countries use varying systems. Some use the medicolegal methods, while others engage the medical examiner and the procurator fiscal system (Offia \& Obiorah, 2014). The main aims for instituting inquest after death include: To avoid secret 
homicides; for official death certification and proper demographic documentation (Obiorah \& Amakiri, 2013). As far back as $44 \mathrm{BC}$, it was recorded that Julius Caesar was the subject of an official autopsy after his murder by rival senators (Obiorah \& Amakiri, 2013). In Nigeria, records showed that the first medicolegal autopsies were in 1917 when the law stipulated that only sudden deaths involving the White colonialists were to be reported to the coroner for autopsy (Amakiri et al., 1997). However, in 1945, a medicolegal autopsy was extended to the indigenous Nigerians, as stated in the Coroner's Laws of Northern Nigeria published in 1963 (Uchendu, Nwachokor, \& Ijomone, 2007).

The rate at which unnatural deaths occur in every society tends to be directly proportional to the law and order situation in a particular jurisdiction. In a society where such indices are low, it implies that the environment is peaceful and harmonious. And this indicates the institutionalisation of sound systems for the security of life and property (Mandong, Manasseh, \& Ugwu, 2006). It can also be an extrapolation for social, mental health and overall, public health indices of the society (Bhulhar, Gorea, \& Aggarwal, 2004). Global trend shows that deaths due to homicides are generally more prevalent among males. Conversely, the demise of females, especially mothers, have serious social, economic, mental, and psychological consequences on the family members and community (Peterson \& Clark, 2006). Besides, gender inequality, domestic violence and burns related deaths appear to be more common among females (Adams, 2008).

In developing countries like ours, where necessary death registrations are deficient, and where a significant number of deaths occur outside the health-care facility, obtaining data for studies on medicolegal autopsies remain a daunting task. However, medicolegal autopsies remain an essential tool for studying unnatural death. Studies of medicolegal deaths of different categories have been publishes within and outside the country to determine the incidence, pattern and prevalence of medicolegal/unnatural deaths (Akhiwu, Nwosu, \& Aligbe, 2000; Duduyemi \& Ojo, 2013; Offia \& Obiorah, 2014; Obiorah \& Amakiri, 2013; Amakiri et al., 1997; Uchendu, Nwachokor, \& Ijomone, 2007; Mandong, Manasseh, \& Ugwu, 2006; Bhulhar, Gorea, \& Aggarwal, 2004). But, there appears to be a dearth of data in the body of literature on medicolegal autopsy in Ebonyi State.

Therefore, this study is determined to study the incidence of medicolegal death and the prevalence of the manner of death in Ebonyi State.

\section{Materials and Method}

\subsection{Study Setting}

Alex Ekwueme Federal University Teaching Hospital (formerly known as Federal Teaching Hospital) Abakaliki is a tertiary hospital within Abakaliki, Ebonyi State, Nigeria. The Hospital receives a referral from all parts of the State and neighbouring States of Benue, Enugu, Cross River and Abia as well as any part of the country. Department of Pathology is one of the ten clinical Departments in the Hospital.

\subsection{Study Design}

This is a 5-year retrospective study undertaken at the Department of Pathology, Alex Ekwueme Federal University Teaching Hospital, Abakaliki, Ebonyi State between January 1, 2013, and December 31, 2017.

\subsection{Study Criteria}

The cases whose deaths were reported to the police and coroner forms issued to carry autopsies on the bodies and postmortem examinations on the corpses carried out at the Department of Pathology. Medical reports of the postmortem were documented on the section for doctor's summary in the coroner form.

\subsection{Data Collection}

The information on the coroner forms was used to obtain personal data of the deceased person, manner of death, type of object used to cause death and type of injury sustained.

\subsection{Statistical Analysis}

The data was entered and analysed using SPSS Version 22.0 (SPSS Inc., Chicago, IL, USA, 2013). Data are presented as mean (standard deviation) or as a percentage with range, as appropriate.

\subsection{Ethical Consideration}

The approval for the study was sought and obtained from the Research and Ethics Committee of Alex Ekwueme Federal University Teaching Hospital, Abakaliki.

\section{Results}

A total number of 202 autopsies were carried out during the period of study. The males accounted for $158(78.2 \%)$, 
and females were $44(21.8 \%)$ given a male to female ratio of 3.6:1. The age of people that were involved ranged from 2 years to 90 years, with a mean age of $35.2 \pm 16.1$. Table 1 showed the age distribution of cases and the age group (30-39 years) as the predominant age group accounting for $61(30.2 \%)$ cases. The age-group 20-29 years 55 $(27.2 \%)$ was the second and the leastage-group 90-99 years with a value of $1(0.5 \%)$. Table 2 showed male preponderance in unnatural deaths, with a total number of 158 cases representing $78.2 \%$ as against 44 cases in females representing $21.8 \%$. Table 3 illustrated that farmers of $31.2 \%$ and students of $15.3 \%$ were mostly affected. Accidental deaths constituted $54.5 \%$, followed by homicidal death while suicidal death was the least, $1 \%$ as shown in Table 4. The analyses of the causes of homicidal deaths in Table 5 indicated that sharp object was the major instrument implicated which accounted for $41.9 \%$ followed by Gun $29.7 \%$ while blunt objects caused $20 \%$ and drowning caused $2 \%$ of the deaths. In accidental deaths in Table 7, Road Traffic Accidents constituted 95. 5\% of deaths while electrocution and drowning were at the same rate of $1.8 \%$ each. The parts of the body that received most impart of the injury was the one which involved multiple sites accounting for $60.4 \%$ while the second most affected site is head with a value of $12.9 \%$. Those parts of the body that were not included in Table 6 are categorised as others, and they constitute $6.9 \%$. There is a combination of injuries in $16.1 \%$ deceased bodies as shown in Table 8; the injuries were as follows: Contusion $27.4 \%$, laceration $24.9 \%$, fractures $26.6 \%$ and penetration $25 \%$.of the deceased bodies. Contusion and fracture had $8.4 \%$, contusion and laceration had $4.1 \%$ while penetration, fracture and abrasion had $3.7 \%$.

Table 1. Age Distribution of sudden Natural Death Cases

\begin{tabular}{lll}
\hline Age group & Frequency & Percentage \\
\hline $0-9 \mathrm{yrs}$ & 10 & $5.0 \%$ \\
$10-19 \mathrm{yrs}$ & 11 & $5.4 \%$ \\
$20-29 \mathrm{yrs}$ & 55 & $27.2 \%$ \\
$30-39 \mathrm{yrs}$ & 61 & $30.2 \%$ \\
$40-49 \mathrm{yrs}$ & 29 & $14.4 \%$ \\
$50-59 \mathrm{yrs}$ & 18 & $8.9 \%$ \\
$60-69 \mathrm{yrs}$ & 13 & $6.4 \%$ \\
$70-79 \mathrm{yrs}$ & 2 & $1.0 \%$ \\
$80-89 \mathrm{yrs}$ & 2 & $1.0 \%$ \\
$90-99 \mathrm{yrs}$ & 1 & $0.5 \%$ \\
Total & 202 & $100.0 \%$ \\
\hline
\end{tabular}

Table 2. Sex

\begin{tabular}{lll}
\hline Sex & Frequency & Percentage \\
\hline Male & 158 & $78.2 \%$ \\
Female & 44 & $21.8 \%$ \\
Total & 202 & $100 \%$ \\
\hline
\end{tabular}


Table 3. Occupation

\begin{tabular}{lll}
\hline Manner & Frequency & Percentage \\
\hline Student & 31 & $15.3 \%$ \\
Driver & 24 & $11,9 \%$ \\
Civil servant & 20 & $9.9 \%$ \\
Tailor & 14 & $6.9 \%$ \\
Trading & 23 & $11.4 \%$ \\
Farmer & 63 & $31.2 \%$ \\
Technician & 9 & $4.5 \%$ \\
Others & 18 & $8.9 \%$ \\
\hline Total & $\mathbf{2 0 2}$ & $\mathbf{1 0 0 \%}$ \\
\hline
\end{tabular}

Table 4. Manner of death

\begin{tabular}{lll}
\hline Manner & Frequency & Percentage \\
\hline Accident & 110 & $54.5 \%$ \\
Homicide & 74 & $36.6 \%$ \\
Suicide & 2 & $1.0 \%$ \\
Undetermined & 16 & $7.9 \%$ \\
Total & 202 & $100.0 \%$ \\
\hline
\end{tabular}

Table 5. Type of homicide

\begin{tabular}{lll}
\hline Homicide & Frequency & Percentage \\
\hline Sharp & 31 & $41.9 \%$ \\
Blunt & 15 & $20.3 \%$ \\
Drowning & 2 & $2.7 \%$ \\
Gun shot & 22 & $29.7 \%$ \\
Strangulation & 4 & $5.4 \%$ \\
\hline Total & $\mathbf{7 4}$ & $\mathbf{1 0 0 . 0 \%}$ \\
\hline
\end{tabular}

Table 6. Site of injury

\begin{tabular}{lll}
\hline Site & Frequency & Percentage \\
\hline Head & 26 & $12.9 \%$ \\
Neck & 11 & $5.4 \%$ \\
Upper limb & 7 & $3.5 \%$ \\
Trunk & 10 & $5.0 \%$ \\
Lower limb & 12 & $5.9 \%$ \\
Multiple sites & 122 & $60.4 \%$ \\
Others & 14 & $6.9 \%$ \\
\hline Total & $\mathbf{2 0 2}$ & $\mathbf{1 0 0 . 0 \%}$ \\
\hline
\end{tabular}


Table 7. Type of Accident

\begin{tabular}{lll}
\hline Accident & Frequency & Percentage \\
\hline RTA & 105 & $95.5 \%$ \\
Electrocution & 2 & $1.8 \%$ \\
Drowning & 2 & $1.8 \%$ \\
Fall from Height & 1 & $0.9 \%$ \\
\hline Total & $\mathbf{1 1 0}$ & $\mathbf{1 0 0 . 0 \%}$ \\
\hline
\end{tabular}

Table 8. Nature of injuries

\begin{tabular}{lll}
\hline Types of Injury & Frequency & Percentage \\
\hline Laceration* & 60 & $24.9 \%$ \\
Contusion* & 66 & $27.4 \%$ \\
Penetration & 25 & $10.4 \%$ \\
Burns & 10 & $4.1 \%$ \\
Fractures* & 59 & $24.5 \%$ \\
Amputation & 4 & $1.7 \%$ \\
Abrasion* & 14 & $5.8 \%$ \\
Others & 3 & $1.2 \%$ \\
\hline Total & $\mathbf{2 4 1}$ & $\mathbf{1 0 0 . 0 \%}$ \\
\hline
\end{tabular}

Some individuals had two to three types of injuries as indicated by the asterisk in $39(16.1 \%)$.

\section{Discussion}

Postmortem examination provides the most reliable approach to determining the cause of death. In this study, the significant finding was that road traffic accident, and homicide constituted the reasons for the majority (91\%) of medicolegal autopsies in this environment. We also found out that medicolegal issues constituted the main reason deceased relatives accept postmortem in this environment, as medicolegal autopsies were responsible for almost $100 \%$ of all postmortem examinations. The significance of this finding is that $54.5 \%$ of these deaths were avoidable and could be controlled by instituting well-structured safe-driving practice and sustainable road maintenance policies. In addition to this, improvement in the security for life and property in this tropical environment is likely to reduce the rate of deaths in our society.

Out of 202 medicolegal autopsies with identified causes of death during the period of this study, there were about threefold incidence in males than females. This result is similar to findings by Mandong et al. in Jos ; Uchendu et al., in Warri and Akhiwu et al.,in Benin. This relative gender discrepancy in unintentional and violent injury-related mortality may be linked to the difference in risk exposure and risk-taking behaviour across both genders. Interestingly, it shows the overall reduced involvement of women in the economic landscape of sub-Saharan Africa. Relatively less number of accidental cases is reported to the coroner resulting in overall low-rate of medicolegal autopsy rate among females. We think that since it is a patriarchal society, there is a socio-cultural tendency to overprotect the female gender, leading to an inherent tendency to report more male death cases to the coroner for investigation than female cases.

Accidental deaths were responsible for $54.5 \%$ of deaths in this study; the significant burden of unintentional deaths is as a result of a road traffic accident which represents the single overall most common cause of death in this study. These victims are mostly pedestrians and passengers as the use of women as commercial motorcycle or vehicle drivers, conductors, or road haulage workers is still unpopular in Nigeria. The high rate of a road traffic accident in Nigeria is attributed to the deteriorating road network, unworthy cars driven by miscreants, the use of motorbikes as significant means of transport, disobedience to safety rules, and lax safety regulating officials (Adams, 2008; Kitulwatte et al., 2017; Edirisinghe \& Kitulwatte, 2009; Albrektsen \& Thomsen, 1989; Dere \& Rojo, 2011). Banning of the use of motorcycles will not only reduce road traffic accident rate but also will reduce the rate of homicide-related deaths in major cities of the country since it has also provided an efficient and flexible 
transportation means for hoodlums.

This study has demonstrated that suicide death is relatively rare in this region, accounting for only $1 \%$ of medicolegal deaths, and lagging behind Accidental and homicide deaths as causes of unnatural death. This Figure is, however, lower than 1.8\%, 1.5\%, reported in Benin City (Akhiwu, Nwosu, \& Aligbe, 2000), Abuja (Duduyemi $\&$ Ojo, 2013), but higher than $0.9 \%, 0.8 \%, 0,5 \%$ and $0.3 \%$ reported in Aba (Offia \& Obiorah, 2014), and Port Harcourt (Obiorah \& Amakiri, 2013), and River State (Amakiri et al.,1997) and Ibadan (Uchendu, Nwachokor, \& Ijomone, 2007). These facts powerfully depict the low rate of suicide may be under-reported. This depressed rate can be attributable to the coroner, or medical examiners feel reluctant at classifying some cases of suicide as such, especially if the supporting data is not convincing. However, because of the intense religious and cultural stigmatisation of relatives of suicide victims, family members are better off if such deaths are concealed or reported to police as non-suicidal cases. Highly religious societies are generally known to have a low suicide rate, and this may be the Nigerian situation (Akhiwu, Nwafor, \& Igbe, 2013; Okafor, 2007). Also although psychiatric illness, frustration, and unemployment abound in our environment, the reduced suicide rate in our environment may also be due to close family ties and supportive, communal living and way of life prevalent in developing economies.

Homicide was responsible for more than one-third of the medicolegal autopsies in this study, affecting mainly the young and the male gender. Most of the deaths that were as a result of homicide were caused by violent use of sharp objects (41.9\%), followed by Gunshot injury $29.7 \%$. This fact is in agreement with the study done in Jos, Nigeria (Mandong, Manasseh, \& Ugwu, 2006); public enlightenment, respect for the rule of law and sustainable security for life and property would reduce the incidence as well as the severity of home and communal violence. Homicide is generally conceived as the killing of an individual by another (Coroner's Law of Northern Nigeria; Cap 27 of 196). However; it is killing of one person by another and criminal homicide as the act of purposefully, knowingly, recklessly or negligently causing the death of another human being. According to Coke in the Nigeria Law Repository, 2014, it is when a man of sound memory and age of discretion, unlawfully killing within any country of the realm any reasonable creature in rerun natural under the king's peace, with malice, aforethought, either expressed by the party or justifiable homicide, murder or manslaughter (Edirisinghe \& Kitulwatte, 2009). Justifiable homicide occurs in self-defence from danger.

In addition, our findings indicated that the peak age range for coroner's autopsies was in the 30 to 39 age range at $37.2 \%$. This differs from the peak age range of 41 to 50 at $36 \%$ on medicolegal autopsies in Jos (Mandong, Manasseh, \& Ugwu, 2006). However, Akhiwu et al. reported a lower peak age of 20 to 29 at 28\%; and Uchendu et al. reported a similar peak age range of 21 to 30 years at 35\% (Akhiwu, Nwosu, \& Aligbe, 2000; Uchendu, Nwachokor, \& Ijomone, 2007). This parallels the peak age of physical and entrepreneurial activity in males. This age also spans through the reproductive age and therefore may be partly related to exposure to intimate partner and domestic violence.

\section{Conclusion}

In conclusion, Road Traffic Accident and Homicidal deaths are the most common form of unnatural death in our environment. They are the typical indication for medicolegal autopsy in the study and are beneficial to the law enforcement and jurisprudence. Although the number of autopsies in our centre are low compared to the southwestern part of the country where there is growing awareness on the benefit of autopsies which may hopefully yield fruitful results in terms of research and auditing of causes of death in our environment.

\section{Competing Interests Statement}

The authors declare that there are no competing or potential conflicts of interest.

\section{References}

Adams, V. I. (2008). Guidelines for reports by autopsy pathologists. Springer Science \& Business Media. https://doi.org/10.1007/978-1-60327-473-9_2

Akhiwu, W. O., Nwafor, C. C., \& Igbe, A. P. (2013). A 20 year retrospective analysis of medicolegal deaths in a tertiary hospital setting in Nigeria. Nigerian journal of clinical practice, 16(4). https://doi.org/10.4103/1119-3077.116910

Akhiwu, W. O., Nwosu, S. O., \& Aligbe, J. U. (2000). Homicide and suicide in benin city, Nigeria. Anil Aggrawal's Internet Journal of Forensic Medicine and Toxicology, 1(2). http://anilaggrawal.com/ij/vol_001_no_002/paper001.html

Albrektsen, S. B., \& Thomsen, J. L. (1989). Detection of injuries in traumatoc deaths. The significance of 
medico-legal autopsy. Forensic science international, $42(1-2), \quad$ 135-143. https://doi.org/10.1016/0379-0738(89)90206-5

Amakiri, C. N. T., Akang, E. E. U., Aghadiuno, P. U., \& Odesanmi, W. O. (1997). A prospective study of coroner's autopsies in University College Hospital, Ibadan, Nigeria. Medicine, Science and the Law, 37(1), 69-75. https://doi.org/10.1177/002580249703700115

Bhullar, D. S., Gorea, R. K., \& Aggarwal, A. D. (2004). Medico-legal autopsy by panel of doctors present scenario. Journal of Indian Academy of Forensic Medicine, 26(3), 113-118.

Coroner's Law of Northern Nigeria; Cap. 27 of 196.

Dere, R. C., \& Rajoo, C. K. (2011). Study of unnatural deaths in females a medicolegal study at rural medical college, Loni. Journal of Indian academy of forensic medicine, 33(3), 211-213.

Duduyemi, B. M., \& Ojo, B. A. (2014). Coroner's Autopsies in Nigeria Capital City of Abuja: A Review of 65 Consecutive Cases. Indian journal of forensic medicine \& toxicology, 8(1), 53-57. https://doi.org/10.5958/j.0973-9130.8.1.011

Edirisinghe, P. A. S., \& Kitulwatte, I. D. G. (2009). Extreme violence-homicide; an analysis of 265 cases from the offices of JMO Colombo and Ragama-a study from Sri Lanka. Legal Medicine, 11, S363-S365. https://doi.org/10.1016/j.legalmed.2009.02.079

Kitulwatte, I. D. G., Edirisinghe, P. A. S., Pratheepa Mendis, H. K. N. L., Wijesinghe, P. R., Fernando, A., \& Abeyrathne, A. R. M. (2017). Study on the pattern of unnatural deaths of women brought for medico-legal autopsy. https://doi.org/10.4038/sljfmsl.v8i1.7789

Mandong, B. M., Manasseh, A. N., \& Ugwu, B. T. (2006). Medicolegal autopsies in North central Nigeria. East African medical journal, 83(11), 626-630. https://doi.org/10.4314/eamj.v83i11.9480

Obiorah, C. C., \& Amakiri, C. N. (2013). Review of population based coroners autopsy findings in Rivers state of Nigeria. Forensic science international, 233(1-3), 1-6. https://doi.org/10.1016/j.forsciint.2013.08.008

Offiah, S. A. U., \& Obiorah, C. C. (2014). Pattern of suicide in Nigeria: the niger Delta experience. Journal of Medical Investigations and Practice, 9(1), 8. https://doi.org/10.4103/atp.atp_44_18

Okafor, E. E. (2007). Sociological implications of communal and ethno-religious clashes in new democratic Nigeria. Studies of Tribes and Tribals, 5(1), 35-45. https://doi.org/10.1080/0972639X.2007.11886557

Peterson, G. F., \& Clark, S. C. (2006). Forensic autopsy performance standards. American Journal of Forensic Medicine and Pathology, 27(3), 200-225. https://doi.org/10.1097/01.paf.0000243580.43150.3c

Uchendu, J. O., Nwachokor, N. F., \& Ijomone, A. E. (2017). Audit of medico legal death in metropolitan city of Warri, Nigeria. International Journal of Forensic Medical Investigation, 3(1), 29-37. https://doi.org/10.21816/ijfmi.v3i1.49

\section{Copyrights}

Copyright for this article is retained by the author(s), with first publication rights granted to the journal.

This is an open-access article distributed under the terms and conditions of the Creative Commons Attribution license (http://creativecommons.org/licenses/by/4.0/). 